\title{
The Neurocognitive Assessment of HIV-Infected School-Aged Nigerian Children*
}

\author{
Gbemisola O. Boyede ${ }^{1,2 \#}$, Foluso E. A. Lesi ${ }^{2}$, Chinyere V. Ezeaka ${ }^{2}$, Charles S. Umeh ${ }^{3}$ \\ ${ }^{1}$ Division of Developmental Paediatrics, School and Child and Adolescent Health, Red Cross War Memorial Children’s Hospital, \\ University of Cape Town, Cape Town, South Africa; ${ }^{2}$ Department of Paediatrics, Lagos University Teaching Hospital, Lagos, Nige- \\ ria; ${ }^{3}$ Clinical Psychology Unit, Department of Psychiatry, Lagos University Teaching Hospital, Lagos, Nigeria. \\ Email: "gbemisola.boyede@uct.ac.za
}

Received January $8^{\text {th }}$, 2013; revised February $10^{\text {th }}$, 2013; accepted February $18^{\text {th }}, 2013$

Copyright (c) 2013 Gbemisola O. Boyede et al. This is an open access article distributed under the Creative Commons Attribution License, which permits unrestricted use, distribution, and reproduction in any medium, provided the original work is properly cited.

\begin{abstract}
Objective: Studies available on cognitive function among school-aged HIV-infected African and in particular Nigerian children are few. The purpose of the study was to assess the neurocognitive function of a group of HIV-infected schoolaged (6 - 15 years) children using the Raven's Standard Progressive Matrices (RPM). Method: Cognitive assessments of 69 HIV positive children and 69 age- and sex-matched apparently healthy HIV negative control children were performed using the Raven's Standard Progressive Matrices (RPM). The children were subdivided (Piaget's developmental staging) into two sub-groups: the concrete operation stage (6 - 11 years) and the formal operation stage (12 - 15 years) for analysis. Result: The mean RPM score for the HIV positive children was 18.2 (8.0 - 47.0, SD 9.8) which was significantly lower than the score of 27.2 (8.0 - 52.0, SD 13.8) for the HIV negative children ( $<0.001)$. On the RPM grading and using the HIV negative children as the standard, $56.5 \%$ of the HIV positive children had cognitive performance at below average to intellectually defective range. Conclusion: School-aged HIV positive children had significantly lower cognitive scores compared with age and gender-matched HIV negative children. Routine neuropsychological evaluation of all school-aged HIV-infected children is recommended. Early detection of cognitive impairment will help in planning appropriate interventions.
\end{abstract}

Keywords: Pediatric HIV; Cognitive Assessment; School-Age Children; Ravens Progressive Matrices; Nigeria

\section{Introduction}

The Human Immunodeficiency Virus (HIV) infection and Acquired Immunodeficiency Syndrome (AIDS) is a global pandemic. Paediatric HIV/AIDS is a significant cause of childhood morbidity and mortality in Africa [1]. In the 2009 AIDS epidemic update, the Joint United Nations Programme on HIV/AIDS (UNAIDS) reported that in 2008, 2.1 million children were living with HIV worldwide and $91 \%$ of this population live in Sub-Saharan Africa [2].

Developmental delays in children with vertically transmitted HIV infection have been well documented [3-7] These delays may begin as early as 4 months of age, continue into the preschool years and manifest as either global or selective delays in neurodevelopment at schoolage [7]. The affected children present with both neuron-

\footnotetext{
*The authors have no financial disclosure or conflict of interest to declare.

${ }^{\#}$ Corresponding author.
}

logical and neuropsychological derangements manifesting as motor and cognitive deficits [8]. However, advances in the medical treatment of children with HIV, including the development and use of combination antiretroviral therapies and supportive medications, not only have prolonged survival but also have promoted growth and development and have improved quality of life [7,8]. Despite these advances, many children still experience direct and indirect effects of HIV infection that affect their experience as effective learners.

Many studies on the impact of HIV on neurodevelopment of infected children have been done among Caucasian infants and preschool-aged children [3-7,9-11]. These studies were quite similar in their findings of delayed neurodevelopment in HIV-infected children. The reports of studies among African infants also demonstrated HIVrelated CNS involvement at similar or higher prevalence rates compared with the Caucasians [12-16]. A systematic review of six published works by Abubakar et al. on 
paediatric HIV/AIDS and neurodevelopment in infancy in Sub-Saharan Africa (SSA) concluded that though HIV has been shown to affect all domains of child functioning, motor development is the most apparent in terms of severity, early onset and persistence across age groups [17].

Studies in the early school-aged and school-aged children are generally lacking especially in Africa where most of the children live. In Africa, the first published study among school-aged HIV-infected children by Bagenda et al. was a longitudinal prospective study of Ugandan children who had never been on antiretroviral therapy (ART) [18]. The authors found no difference in the cognitive performance of HIV-infected children and the control HIV negative children using the Kaufmann Assessment Battery for Children (K-ABC) and the Wide Range Achievement, third editions (WRAT-3) instruments for cognitive assessments. The authors reasoned that perhaps, the children in the original cohort with severe HIV encephalopathy had died leaving this subgroup of children with a static/stable expression of the disease that performed at normal or near-normal range in the cognitive assessments.

There is need for more research especially among African children beyond the preschool-age period. This is important as many children now survive up to school-age in Africa due to free antiretroviral therapy in many countries including Nigeria. It is crucial to ascertain the impact of HIV on their cognitive abilities with possible effect on their academic achievement. Currently, neuronpsychological assessment is not part of the routine care of the HIV-infected children in Nigeria. The purpose of this study was to assess the neurocognitive function of HIV-infected school-aged children with the Raven's Standard Progressive Matrices (RPM).

\section{The Instrument}

The Raven's Progressive Matrices (RPM) is a widely used nonverbal test of general intelligence that appraises visuo-spatial reasoning, abstract thinking, deductive reasoning and general intelligence [19]. RPM has been validated for use in Nigerian children [20]. In RPM, a person is shown a matrix of patterns with one pattern missing. The person must figure out the rules governing the patterns and then use these rules to pick the item that best fills in the missing pattern. The test was designed to minimize the influence of culture by relying on nonverbal problems that require abstract reasoning and do not require knowledge of a particular culture. The RPM consists of sixty problems divided into five subsets of twelve. Each person's total score is the total number he/she got correctly.

\section{Methods}

\subsection{Study Location}

The study was a cross-sectional study conducted between November 2009 and April 2010 at Lagos University Teaching Hospital (LUTH), Lagos State, Nigeria. LUTH is a 750-bedded tertiary centre providing healthcare to inhabitants of Lagos and neighbouring states. Children below the age of eighteen years have health care provided through the Department of Paediatrics at LUTH. Services provided include emergency paediatric services, inpatient care and specialty outpatient clinics which include a dedicated Paediatric HIV Clinic for HIV-infected and HIV-exposed children.

\subsection{Study Participants}

HIV-infected children at school-age (6 - 15 years) accessing care at Paediatric HIV Clinic, LUTH constituted the study population. The total number of children (comprising of infants perinatally exposed to HIV and HIVinfected children) attending the clinic at the end of 2009 was 566 out of which 223 were within the age group 6 15 years. The latter group had 174 children on HAART while 49 were not on HAART. The Clinic is being funded by the USA government through the President's Emergency Plan for AIDS Relief (PEPFAR). The HIV-infected children were being managed according to the National Guidelines for Paediatric HIV/AIDS treatment and care based on the clinical and immunological stage of their disease [21]. Human Immunodeficiency Virus infection was diagnosed with a positive Enzyme Linked Immunosorbent Assay (ELISA) test, which was confirmed with the Western blot test. HIV-infected children who presented at age below eighteen months had HIV diagnosis confirmed with the HIV DNA PCR tests.

The HIV positive subjects were recruited from consecutive HIV-infected children attending the Paediatric HIV (APIN) clinic. The HIV negative children controls were drawn from among children within the same agerange attending follow-up clinics at the Paediatric Outpatient Clinics. The parents were offered provider-initiated counselling and testing (PITC) of their wards. The children of parents/guardians who consented were tested for HIV at the APIN clinic. Pre- and post-test counselling is usually provided for all individuals being tested at this centre. The children who tested negative for HIV were recruited into the study.

\subsection{Inclusion Criteria for Subjects}

1) Confirmed HIV positive status;

2) Age 6 - 15 years inclusive;

3) HIV status disclosure (partially or fully) to the child by the parents and/or counselors and signed, informed 
consent by the parents/guardians as well as the assent (verbal/written) of the children.

The control had same inclusion criteria except having negative HIV status

\subsection{The Exclusion Criteria for Subjects and Controls}

1) Acute illness and/or hospital admission at the time of cognitive test administration;

2) Chronic neurological disorders such as epilepsy, cerebral palsy;

3) Inability to perform the RPM cognitive test for whatever reasons.

\subsection{Procedure and Data Collection}

Consecutive HIV positive children attending the Paediatric HIV Clinic and the HIV negative controls seen at the Paediatric Outpatient Clinics who satisfied the inclusion criteria were recruited until the desired sample sizes were attained. After obtaining informed consents/assents from the parents/children, the researcher administered the study proforma. The proforma consisted of five sections: 1) socio-demographic data; 2) medical history; 3) neurological symptoms 4) neurological examination and 5)
RPM cognitive tests. The socioeconomic status of the family of the subjects was computed using the method recommended by Oyedeji [22]. HIV positive children had their disease staged using the WHO clinical staging [23].

\subsection{Ethical Approval}

The study was approved by the LUTH Research and Ethics Committee before the commencement of the study. Informed, written consents were obtained from the parents/guardians and verbal/written assents were obtained from the participants. The children were informed of their scores and parents/caregivers were counseled on need for follow-up care.

\subsection{Data Analysis}

Data was entered, validated and analyzed using the SPSS for windows version 16.0. [24]. A p value less than 0.05 was accepted as statistically significant (two-tailed analysis).

\section{Results}

One hundred and thirty-eight children made up of 69 HIV positive subjects and 69 HIV negative controls were recruited into the study. Table 1 shows the socio-demographic characteristics of the HIV positive and the HIV

Table 1. Socio-demographic characteristics of study subjects.

\begin{tabular}{|c|c|c|c|}
\hline Characteristics & HIV positive $N=69$ & HIV negative $N=69$ & p value \\
\hline Age (years) & $9.86 \pm 2.48$ & $9.64 \pm 2.42$ & 0.61 \\
\hline $\begin{array}{c}\text { Age (years) } \\
6-11 \\
12-15\end{array}$ & $\begin{array}{l}55(80 \%) \\
14(20 \%)\end{array}$ & $\begin{array}{l}55(80 \%) \\
14(20 \%)\end{array}$ & 1.00 \\
\hline $\begin{array}{l}\text { Sex } \\
\quad \text { Male } \\
\text { Female }\end{array}$ & $\begin{array}{l}34(49.3 \%) \\
35(50.7 \%)\end{array}$ & $\begin{array}{l}33(47.8 \%) \\
36(52.2 \%)\end{array}$ & 0.87 \\
\hline $\begin{array}{l}\text { Level of education } \\
\text { Nursery } \\
\text { Primary } \\
\text { Junior secondary } \\
\text { Senior secondary }\end{array}$ & $\begin{array}{c}4(5.8 \%) \\
52(75.4 \%) \\
10(14.5 \%) \\
3(4.3 \%)\end{array}$ & $\begin{array}{c}1(1.5 \%) \\
51(73.9 \%) \\
12(17.4 \%) \\
5(7.2 \%)\end{array}$ & 0.48 \\
\hline $\begin{array}{l}\text { Socio-economic class } \\
\text { Upper (I and II) } \\
\text { Middle (III) } \\
\text { Lower (IV and V) }\end{array}$ & $\begin{array}{l}26(37.7 \%) \\
28(40.6 \%) \\
15(21.7 \%)\end{array}$ & $\begin{array}{c}45(65.2 \%) \\
16(23.2 \%) \\
8(11.6 \%)\end{array}$ & $0.01^{*}$ \\
\hline $\begin{array}{l}\text { Primary caregiver } \\
\text { Mother } \\
\text { Others }\end{array}$ & $\begin{array}{l}53(76.8 \%) \\
16(23.2 \%)\end{array}$ & $\begin{array}{l}51(73.9 \%) \\
18(26.1 \%)\end{array}$ & 0.69 \\
\hline $\begin{array}{l}\text { Mother's level of educ } \\
\text { Tertiary } \\
\text { Secondary } \\
\text { Primary } \\
\text { None }\end{array}$ & $\begin{array}{c}15(21.7 \%) \\
35(50.7 \%) \\
16(23.3 \%) \\
3(4.3 \%)\end{array}$ & $\begin{array}{c}39(56.5 \%) \\
21(30.4 \%) \\
7(10.1 \%) \\
2(2.9 \%)\end{array}$ & $0.001^{*}$ \\
\hline $\begin{array}{l}\text { Mother's HIV status } \\
\text { Positive } \\
\text { Negative } \\
\text { Unknown }\end{array}$ & $\begin{array}{c}53(76.8 \%) \\
8(11.6 \%) \\
8(11.6 \%)\end{array}$ & $\begin{array}{c}0(0.0 \%) \\
40(58.0 \%) \\
29(42.0 \%)\end{array}$ & $0.001^{*}$ \\
\hline
\end{tabular}


negative subjects. The mean age of the HIV positive children was $9.86 \pm 2.48$ years. The HIV positive and HIV negative children were comparable in terms of age, gender distribution, level of education and primary caregivers. Thirty-nine of the HIV positive subjects were receiving HAART.

\subsection{The RPM Cognitive Scores of HIV Positive and HIV Negative Subjects}

The overall mean RPM score for the HIV positive children was 18.2 (8.0 - 47.0, SD 9.8) which was lower than the mean score of 27.2 (8.0 - 52.0, SD 13.8) for the HIV negative children as shown in Table 2 . The difference was statistically significant ( $<<0.001)$. The mean RPM score of the HIV positive subjects in the age group 6 - 11 years was 15.5 while their HIV negative counterparts had a mean score of $24.9(\mathrm{p}<0.001)$. In the age group 12 15 years, the mean RPM score of the HIV positive children was 28.8, also higher than the score of 36.2 by the HIV negative control children. However, the difference failed to reach statistical significance $(p=0.06)$.

\subsection{RPM Grading of the HIV Positive and HIV Negative Subjects}

The distribution of the study subjects by RPM grading is shown on Table 3. For Chi-square analysis, the grading was dichotomized to scores that were at least average and above; and scores below average as shown in Table 4. About two-third of the HIV negative children had RPM scores that were at least average and above compared to less than half of the HIV positive subjects with same grade scores. Conversely, more than half of HIV positive children had RPM scores at below average and lower grades compared with one-third of the HIV negative children with similar grades. This difference was statistically significant $\left(\chi^{2}=7.50, \mathrm{p}=0.006\right)$.

\section{Discussion}

The finding of lower RPM cognitive scores by HIV positive children compared with HIV negative control children is similar to reports of other studies among schoolaged HIV positive children in USA and Greece [25,26].

Table 2. Age and RPM scores of HIV negative and HIV positive children.

\begin{tabular}{|c|c|c|c|c|c|c|}
\hline \multirow{3}{*}{ Age Group } & \multicolumn{4}{|c|}{ RPM scores } & \multirow{3}{*}{ t value } & \multirow{3}{*}{ p value } \\
\hline & \multicolumn{2}{|c|}{ HIV- } & \multicolumn{2}{|c|}{ HIV+ } & & \\
\hline & $\mathbf{N}$ & Mean \pm SD & $\mathbf{n}$ & Mean \pm SD & & \\
\hline $6-11$ & 55 & $24.9 \pm 13.1$ & 55 & $15.5 \pm 6.9$ & -4.75 & $0.00^{*}$ \\
\hline $12-15$ & 14 & $36.2 \pm 13.3$ & 14 & $28.8 \pm 12.6$ & -1.54 & 0.14 \\
\hline
\end{tabular}

" $\mathrm{p}$ value significant; HIV- = HIV negative children; HIV+ = HIV positive children.

Table 3. RPM grading of HIV positive and HIV negative children.

\begin{tabular}{lccc}
\hline \multicolumn{1}{c}{ RPM grade } & HIV+ n (\%) & HIV-n (\%) & Total n (\%) \\
\hline Grade 1 (superior) & $1(1.4 \%)$ & $5(7.2 \%)$ & $6(4.3 \%)$ \\
Grade 2 (above average) & $1(1.4 \%)$ & $15(21.7 \%)$ & $16(1.6 \%)$ \\
Grade 3 (average) & $28(40.6 \%)$ & $26(37.7 \%)$ & $54(39.1 \%)$ \\
Grade 4 (below average) & $27(39.1 \%)$ & $16(23.2 \%)$ & $43(31.2 \%)$ \\
Grade 5 (intellectual deficit) & $12(17.4 \%)$ & $7(10.1 \%)$ & $19(13.8 \%)$ \\
\hline
\end{tabular}

HIV+ = HIV positive children; HIV- = HIV negative children.

Table 4. Distribution of rpm grading and HIV status.

\begin{tabular}{ccc}
\hline Rpm grading & HIV+ & HIV- \\
\hline Average and above & $30(43.4 \%)$ & $46(66.7 \%)$ \\
Below average & $39(66.6 \%)$ & $23(33.3 \%)$ \\
\hline
\end{tabular}

$\left(\chi^{2}=7.50, \stackrel{*}{p}=0.006\right)$. 
In the present study, $56.5 \%$ of the HIV positive children also had cognitive performance at below average to intellectual deficit range using the HIV negative children as the standard. This finding is comparable to that by Papola et al. [25] among school-aged HIV-infected American children where $56 \%$ were reported to be functioning at below average to mentally retarded range. The latter study had the largest sample of 90 school-aged HIVinfected children studied so far in the USA. The age range of the American children (5 - 14) was similar to the present study. In addition, the subjects were clinically stable at the time of their assessments and majority (82\%) was on antiretroviral therapy [25]. HAART has been shown to halt and/or possibly reverse progression of HIV-associated encephalopathy [27]. However, despite the clinical stability and use of anti-retroviral medications, there is still ongoing cognitive decline mostly attributable to the HIV infection. The lower cognitive scores among HIV positive children have also been documented in a study in Greece [26]. All HIV positive subjects in the Greece study were also on antiretroviral therapy as in the present study. This suggests that HAART may not completely reverse established encephalopathy in all cases. The finding of poorer cognitive performance by HIV-infected children compared with HIV negative children even during periods of clinical stability shows the need for routine neuropsychological evaluation of HIV-infected children for early detection of those with cognitive deficits.

However, few studies have also shown no difference in cognitive scores among HIV positive and HIV negative children at school age. In Uganda, Bagenda et al. found no statistical significant difference in cognitive scores of the school-aged HIV positive and the HIV negative control children using the Kaufmann Assessment Battery for Children (KABC) which has non-verbal sub-sections similar to the RPM [18]. The HIV-infected children in the Ugandan study had never been on antiretroviral therapy and were long-term survivors of a cohort of perinatally HIV-infected children. This is in contrast to the present study which included HIV-infected children on HAART. It is possible that the children in the Ugandan cohort with severe illness who would probably have had cognitive impairments had died leaving those children with a more clinically stable form of HIV disease in this study with cognitive performance at near normal range. Tardieu et al. also in France also reported HIV-infected children to have cognitive function at normal range [28]. All the French children were ambulatory and neurologically stable, with majority on antiretroviral therapy comparable to HIV-infected children in the current study. The French Study was however not controlled. It is known that manifestation of HIV associated encephalopathy vary among infected children [29]. However, it is not clearly known why one group of infected children develops more severe form of encephalopathy compared to others. The Ugadan and French studies also had a relatively few sample size $(\mathrm{N}=28)$ compared to present and American studies which found significant difference. The lack of consistency in the findings of the studies among HIV-infected school-age children may also be due to difference in methods used in evaluating cognitive function by various studies. This has been one of the major challenges in comparing studies among school-age children.

The present study has few limitations. It was a crosssectional study with just one cognitive assessment. A longitudinal prospective follow-up cohort study from birth with multiple interval assessments over a time period would have given more information about cognitive deficits over time and also control for birth-related parameters and events. Secondly, different domains of cognitive function were not assessed. This was because of the need to perform a brief cognitive test that can be done on outpatient basis. Also, we were unable to correlate the performance on RPM cognitive test with the current academic and school performance of the study subjects.

\section{Conclusions}

This study has shown that the cognitive RPM scores of clinically and neurologically stable school-aged HIVinfected children aged 6 - 11 years was significantly lower than that of the age- and gender-matched HIV negative control children. We therefore recommend that all HIV positive Nigerian children should have routine neuropsychological evaluation at intervals as part of their standard care to promptly detect children with cognitive impairment for early interventions.

However, there is still the need for more research preferably longitudinal follow-up cohort studies which will include multiple interval cognitive assessments among Nigerian children to further confirm the findings of this preliminary study. The findings on cognitive assessments should also be correlated with the current academic performance.

\section{Acknowledgements}

We thank all the parents and children attending Paediatric HIV (APIN) and Paediatric Outpatient Clinics who participated in this study. We also acknowledge the laboratory and data room staff of APIN clinic for their assistance during the course of the study.

\section{REFERENCES}

[1] D. Tindyebwa, J. Kayita, P. Musoke, B. Eley, R. Nduati, H. Coovadia, R. Bobart, D. Mbori-Ngacha and M. Kieffer, "Handbook on Paediatric AIDS in Africa," African Net- 
work for the Care of Children Affected by AIDS, 2006.

[2] Joint United Nation Programme on HIV/AIDS (UNAIDS), “AIDS Epidemic Update,” 2009. http://www.unaids.org

[3] C. Chase, J. Ware, J. Hittelman, I. Blasini, R. Smith, A. Llorente, E. Anisfeld, C. Diaz, M. Fowler, D. Moye and L. Kaligh, "Early Cognitive and Motor Development among Infants Born to Women Infected with Human Immunodeficiency Virus: Women and Infants Transmission Study Group,” Pediatrics, Vol. 106, No. 2, 2000, p. e25. doi:10.1542/peds.106.2.e25

[4] E. Cooper, C. Hanson, C. Diaz, H. Mendez, R. Abboud, R. Nugent, J. Pitt, K. Rich, E. Rodriguez and V. Smeriglio, "Encephalopathy and Progression of Human Immunodeficiency Virus Disease in a Cohort of Children with Perinatally Acquired Human Immunodeficiency Virus Infection: Women and Infants Transmission Study Group,” Journal of Pediatrics, Vol. 132, No. 2, 1998, pp. 808-812. doi:10.1016/S0022-3476(98)70308-7

[5] C. Mellins, R. Levenson, R. Zawadzki, R. Kairam and M. Weston, "Effects of Pediatric HIV Infection and Prenatal Drug Exposure on Mental and Psychomotor Development," Journal of Pediatric Psychology, Vol. 19, No. 5, 1994, pp. 617-628. doi:10.1093/jpepsy/19.5.617

[6] P. Wolters, P. Brouwers, H. Moss and P. Pizzo, "Differential Receptive and Expressive Language Functioning of Children with Symptomatic HIV Disease and Relation to CT Scan Brain Abnormalities,” Pediatrics, Vol. 95, No. 1, 1995, pp. 112-119.

[7] R. Smith, K. Malee, R. Leighty, P. Brouwers, C. Mellins, J. Hittelman, C. Chase and I. Blasini, "Effects of Perinatal HIV Infection and Associated Risk Factors on Cognitive Development among Young Children,” Pediatrics, Vol. 117, No. 3, 2006, pp. 851-862. doi:10.1542/peds.2005-0804

[8] L. Millana-Cuevas, J. Portellano and R. Martinez-Arias, "Neuropsychological Impairment in Human Immunodeficiency Virus-Positive Children," Revista de Neurología, Vol. 44, No. 6, 2007, pp. 366-374.

[9] G. Diamond, P. Gurdin, A. Wiznia, A. Belman, A. Rubinstein and H. Cohen, "Effects of Congenital HIV Infection on Neurodevelopmental Status of Babies in Foster Care," Developmental Medicine \& Child Neurology, Vol. 32, No. 11, 1990, pp. 999-1005. doi:10.1111/j.1469-8749.1990.tb08123.x

[10] R. Levenson, C. Mellins, R. Zawadzki, R. Kairam and Z. Stein, "Cognitive Assessment of Human Immunodeficiency Virus-Exposed Children," American Journal of Diseases of Children, Vol. 146, No. 12, 1992, pp. 1479-1483.

[11] P. Fishkin, F. Armstrong, D. Routh, L. Harris, W. Thompson, K. Miloslavich, J. Levy, A. Johnson, C. Morrow, E. Bandstra, C. Mason and G. Scott, "Brief Report: Relationship between HIV Infection and WPPSI-R Performance in Preschool-Age children," Journal of Pediatric Psychology, Vol. 25, No. 5, 2000, pp. 347-351. doi:10.1093/jpepsy/25.5.347

[12] P. Msellati, P. Lepage, D. Hitimana, C. Van Goethem, P. Van de Perre and F. Dabis, "Neurodevelopmental Testing of Children Born to Human Immunodeficiency Virus Type 1 Seropositive and Seronegative Mothers: A Prospective
Cohort Study in Kigali, Rwanda,” Pediatrics, Vol. 92, No. 6, 1993, pp. 843-848.

[13] D. Drotar, K. Olness, M. Wiznitzer, L. Guay, L. Marum, G. Svilar, D. Hom, J. Fagan, C. Ndugwa and R. KiziriMayengo, "Neurodevelopmental Outcomes of Ugandan Infants with Human Immunodeficiency Virus Type 1 Infection," Pediatrics, Vol. 100, No. 1, 1997, p. e5. doi:10.1542/peds.100.1.e5

[14] M. Boivin, S. Green, A. Davies, B. Giordani, J. Mokili and W. Cutting, "A Preliminary Evaluation of the Cognitive and Motor Effects of Pediatric HIV Infection in Zairian Children," Health Psychology, Vol. 14, No. 1, 1995, pp. 13-21. doi:10.1037/0278-6133.14.1.13

[15] N. McGrath, D. Bellinger, J. Robins, G. Msamanga, E. Tronick and W. Fawzi, "Effect of Maternal Multivitamin Supplementation on the Mental and Psychomotor Development of Children Who Are Born to HIV-1-Infected Mothers in Tanzania,” Pediatrics, Vol. 117, No. 2, 2006, pp. e216-e225. doi:10.1542/peds.2004-1668

[16] A. Van Rie, A. Mupuala and A Dow, "Impact of the HIV/ AIDS Epidemic on the Neurodevelopment of PreschoolAged Children in Kinshasa, Democratic Republic of the Congo,” Pediatrics, Vol. 122, No. 1, 2008, pp. e123-e128. doi:10.1542/peds.2007-2558

[17] A. Abubakar, A. Van Baar, F. Van de Vijver, P. Holding and C. Newton, "Paediatric HIV and Neurodevelopment in Sub-Saharan Africa: A Systematic Review," Tropical Medicine \& International Health, Vol. 13, No. 7, 2008, pp. 880-887. doi:10.1111/j.1365-3156.2008.02079.x

[18] D. Bagenda, A. Nassali, I. Kalyesubula, B. Sherman, D. Drotar, M. Boivin and K. Olness, "Health, Neurologic, and Cognitive Status of HIV-Infected, Long-Surviving, and Antiretroviral-Naive Ugandan Children,” Pediatrics, Vol. 117, No. 3, 2006, pp. 729-740. doi:10.1542/peds.2004-2699

[19] J. Raven, “Standard Progressive Matrices,” H. K. Lewis, London, 1958.

[20] O. Ogunlade, “The Predictive Validity of the Raven's Progressive Matrices with Some Nigerian Children," Educational and Psychological Measurement, Vol. 38, No. 2, 1978, pp. 465-467. doi:10.1177/001316447803800232

[21] Federal Ministry of Health, "National Guidelines for Paediatric HIV and AIDS Treatment and Care,” Federal Ministry of Health, HIV and AIDS Division, Abuja, 2007.

[22] G. A. Oyedeji, "Socioeconomic and Cultural Background of Hospitalized Children in Ilesa," Nigerian Journal of Paediatrics, Vol. 12, No. 4, 1985, pp. 111-117.

[23] World Health Organization, "Revised WHO Paediatric Clinical Staging System,” WHO, Geneva, 2006.

[24] SPSS for Windows (Computer Programme), Release 16.0.1, SPSS Inc., Chicago, 2007.

[25] P. Papola, M. Alvarez and H. Cohen, "Developmental and Service Needs of School Children with HIV," Pediatrics, Vol. 94, No. 6, 1994, pp. 914-918.

[26] G. Bertou, L. Thomaidis, V. Spoulou and M. Theodoridou, "Cognitive and Behavioral Abilities of Children with HIV Infection in Greece,” Pediatrics, Vol. 121, No. 2, 2008, p. S100. doi:10.1542/peds.2007-2022BB 
[27] C. Chiriboga, S. Fleishman, S. Champion, L. Gaye-Robinson and E. Abrams, "Incidence and Prevalence of HIV Encephalopathy in Children with HIV Infection Receiving Highly Active Anti-Retroviral Therapy (HAART)," Journal of Pediatrics, Vol. 146, No. 3, 2005, pp. 402-407. doi:10.1016/j.jpeds.2004.10.021

[28] M. Tardieu, M. Mayaux, N. Seibel, I. Funck-Brentano, E. Straub, J. Teglas and S. Blanche, "Cognitive Assessment of School-Age Children Infected with Maternally Trans- mitted Human Immunodeficiency Virus Type 1,” Journal of Pediatrics, Vol. 126, No. 3, 1995, pp. 375-379. doi:10.1016/S0022-3476(95)70451-5

[29] W. Mitchell, "Neurological and Developmental Effects of HIV and AIDS in Children and Adolescents," Mental Retardation and Developmental Disabilities Research Reviews, Vol. 7, No. 3, 2001, pp. 211-216.

doi:10.1002/mrdd.1029

\section{Abbreviations}

APIN: Aids Prevention in Nigeria

HAART: Highly Active Antiretroviral Therapy

PEPFAR: President's Emergency Plan for AIDS Relief

RPM: Raven's Standard Progressive Matrices 